\title{
Surface Energetics Study and Determination of the Combined Negative Hamaker Coefficient for Hepatitis C Virus Infected Human Blood Cells
}

\author{
C. H. Achebe ${ }^{1}$, S. Iweriolor ${ }^{2}$, J. L. Chukwuneke ${ }^{1}$
}

${ }^{1}$ Department of Mechanical Engineering, Nnamdi Azikiwe University, Awka, Nigeria; ${ }^{2}$ Department of Mechanical Engineering, Delta State Polytechnic, Ogwashi-Uku, Nigeria

Correspondence to: S. Iweriolor, sundaytrevor1234@gmail.com

Keywords: Absolute Hamaker Coefficient, Blood Components, Contact Angle, Hepatitis C, Lymphocytes, Surface Energetics

Received: November 1, $2018 \quad$ Accepted: November 23, $2018 \quad$ Published: November 26, 2018

Copyright (C) 2018 by authors and Scientific Research Publishing Inc.

This work is licensed under the Creative Commons Attribution International License (CC BY 4.0).

http://creativecommons.org/licenses/by/4.0/

\section{(c) (i) Open Access}

\section{ABSTRACT}

This study investigated the interactive effects of Hepatitis $C$ virus on human cells using the contact angle approach. The methodology involves the use of sessile drop approach to determine the contact angle formed on the infected and uninfected blood cells in the presences of glycerin as the probe liquid. It was observed that the presence of the virus in the human blood cells depleted the immune system of infected cells giving rise to a decreased CD4 count on the average of $514.5 \pm 243.10$ when compared with the uninfected cells CD4 count of $1267.2 \pm 368.27$. The measurement of contact angle also unveils that among the blood components separated in the course of the experiment, the white blood cell is the principal target of the virus with the highest average contact angle of $63.4 \pm 3.20$ while the uninfected white blood cells have a lower contact angle of $48.5 \pm 2.75$. The result of the measured contact angle was used for MATLAB computation to determine the surface energy, force of adhesion and the Hamaker coefficient. Response surface methodology was also employed in this study to visualize the viral impact on the blood cells as well as generating model equations for prediction of the interaction between the virus and the blood cells. Infected surfaces on the average have higher values of Hamaker coefficient than uninfected surfaces. It was discovered that an increase in the contact angles causes a significant increase in Hamaker coefficient with a corresponding decrease in the CD4 counts on the infected surfaces. This increase is attributed to the presence of the HCV virus in the infected samples and the highest value was observed in the white blood cell component. Computation of the combined negative Hamaker coefficient revealed that there exists a possibility of separating the 
virus from the human lymphocyte, hence a negative value of the $A_{132}$ of the infected sample was seen to be $-0.150 \times 10^{-18} \mathrm{~mJ} / \mathrm{m}^{2}\left(-0.150 \times 10^{-25} \mathrm{~J}\right)$. This is in agreement with the value reported in literature when an alternative method to contact angle was used (ultraviolent spectrophotometer approach) to investigate HIV infected human cells. The combined negative Hamaker coefficient of $-0.281 \times 10^{-25} \mathrm{~J}$ was obtained in that study. Both results have unveiled the possibility of applying the concept of combined negative Hamaker coefficient as a means of separating the virus from the lymphocytes. It therefore implies that additives in the form of drug(s) to the serum (as an intervening medium) which could alter the surface energy of the serum to a value of $\geq-0.150 \times 10^{-25} \mathrm{~J}$ can have the capability of totally isolating the virus from the lymphocytes.

\section{INTRODUCTION}

Hepatitis $\mathrm{C}$ is a global health burden to both industrialized and developing countries infecting an estimated 3\% of the world population. It represents a viral pandemic that is $4-5$ times more prevalent than HIV infection, therefore the reduction of global mortality and morbidity related to hepatitis $\mathrm{C}$ is of great concern to public health [1]. It is an infectious disease affecting the liver with no symptoms at the initial stage of the infection and at long term impact of chronic infection causes permanent liver damage, cirrhosis, hepatocellular carcinoma and even death [2]. Despite infecting a great number of people worldwide, the global burden of $\mathrm{HCV}$ infection remains at large a silent epidemic because acute infection is generally asymptomatic and morbidity and mortality arise only after years of infection [3]. As at 2018, no approved vaccine protects against hepatitis $C$ virus [4], prevention includes testing of donated blood, harm reduction efforts among people who use intravenous drugs. However enormous advances have been made in the treatment of hepatitis $\mathrm{C}$ virus infection, currently the combination of pegylated interferon-alpha and ribavirin (RBV) is the standard treatment for the infection and it has so far achieved less than $50 \%$ success with each HCV genotype showing differences in sustained virological response (SVR) to therapeutic strategy, especially genotype 1 regarded as more problematic showing less than 50\% HCV clearance [5].

\subsection{Thermodynamic Approach to Hepatitis C Virus and Blood Cells Interaction}

Before now, treatment successes recorded from the use of antiviral drugs has been achieved from various markers such as CD4 cell counts, virology and immunology. Sustained virological response is achieved when the antiviral on continued administration reduces the viral load of HCV to clinically undetectable levels within the first 12 - 24 weeks. Within this period, the immunological response by virtue of the steady administration of the drugs on the HCV infected blood is the increase of CD4 cell count. Clinically, the symptoms of the infection as believed will subside within this period. However these antiviral drugs do not eliminate totally the virus from the blood stream and only provides a functional cure with side effects. It is against this backdrop that this study has looked beyond the clinical approach and is anchored on the thermodynamic response by determining the net repulsive van der Waal forces between the $\mathrm{HCV}$ and the lymphocytes. A negative value of the van der Waal forces of interaction (Hamaker Coefficient) suggests total separation of the virus from the blood cell. The interaction between the HCV-RNA can be likened to particle-particle interactions [6].

Mechanism of interactions can be achieved with an in-depth knowledge of the surface properties determination of the interacting particles. A common area of contact is established as soon as two particles meet each other. Therefore, a certain portion of each particle gets displaced through work. Work responsible for the displacement of a unit area is known as surface free energy. The consecutive impact on the surface is known as surface thermodynamic effects. In this particular study similar occurrence can be envisaged to characterize the HCV-RNA particles [7]. 
The attraction and repulsion of particles in a fluid medium was made explicit in the classical works of Hamaker when he established that "if two particles are embedded in a fluid and the London van der waal forces between the particle and the fluid is greater than the particles themselves, it might be thought that it will result in repulsion rather than attraction". Owing to a peculiar property of London van der waal forces, the resultant force is generally attractive even when the particles are surrounded by the fluid [8]. When two bodies interact in a liquid medium, separation will occur due to dispersion forces only if the attraction of the bodies with the liquid is higher than that between the bodies themselves.

The sign of a net van der Waal interaction between two different solid bodies or between two dissolved macromolecules in a liquid is often negative even if they are electrically neutral and even in polar liquids [9].

Now the new capability to change the attraction between solids submerged in liquids or dissolved molecules into repulsion have a considerable impact in separation methods. This will help throw an insight into the possibility of separating the HCV particles from the blood cells which forms the basis of drug design for the treatment of HCV.

Considering Hamaker expression for the free energy for such bodies in a liquid medium;

$$
\Delta F(d)=-\frac{A_{132}}{12 \pi d^{2}}
$$

where $\Delta F$ is change in energy of adhesion, $d$ is separation distance and $A_{132}$ is combined Hamaker coefficient.

Assuming a minimum separation distance, $d_{o}$ and Equation (1.1) is still valid for small separation distance, the Hamaker coefficient can now be expressed as;

$$
A_{132}=-12 \pi d^{2} \Delta F^{a d h}(d)
$$

From the foregoing, the Hamaker coefficient can be calculated once the free energy of adhesion between two bodies is known.

$$
\Delta F_{123}^{a d h}=\gamma_{12}-\gamma_{13}
$$

$\gamma_{12}$ is interfacial energy between the bodies in contact, $\gamma_{13}$ is tension between solid and the serum

However, if the value of $A_{132}$ becomes closer to zero than $\approx \mp 3.5 \times 10^{-15}$ ergs $\left(3.5 \times 10^{-22} \mathrm{~J}\right)$, an exact prediction of attraction and repulsion based on whether $A_{132}$ is positive or negative may no longer be reliable and this calls for a different separation method.

The following criteria must be fulfilled for this situation to occur; $A_{132}<0$ only when;

$$
\begin{gathered}
\sqrt{A_{11}}>\sqrt{A_{33}} \text { and } \sqrt{A_{22}}<\sqrt{A_{33}} \\
\sqrt{A_{11}}<\sqrt{A_{33}}<\sqrt{A_{22}} \\
\sqrt{A_{11}}<\sqrt{A_{33}}<\sqrt{A_{22}} \text { or } \sqrt{A_{11}}>\sqrt{A_{33}}>\sqrt{A_{22}} \\
A_{132}=\left(\sqrt{A_{11}}-\sqrt{A_{33}}\right)\left(\sqrt{A_{22}}-\sqrt{A_{33}}\right)
\end{gathered}
$$

In relation to this study, $A_{11}, A_{22}$ and $A_{33}$ are Hamaker constants for uninfected white blood cell, infected lymphocyte and serum respectively [10].

\subsection{Surface Tension of Blood Cells and Proteins}

Pathological features of diseases vary in the nature and the magnitude. Despite this diversity, the common feature of various disorders underlies the physiochemical and biochemical factors such as surface tension. Changes in the surface tension behavior of human biological fluid are characteristic for some diseases. Studying these interfaces and the changes that occur will provide valuable information relating to various diseases and help to monitor the treatment efficacy. Biological tissues are viscoelastic materials and 
the cells in a tissue behave very much like molecules in a fluid. This property enables them to change their position and move against each other. The morphology and shape of the organism are driven by the events that occur at the cellular level. The shape of a cell is the result of a balance of intracellular and extrinsic forces exerted on it. This behavior is defined through surface tension which tends to minimize the exposed area of the cell aggregate and maximize the cohesive forces. The intracellular forces on the membrane are a result of the cytoskeleton reorganization. Energy at the cellular level is usually measured through physical properties such as cell adhesion, viscosity, and cortical tension. Several approaches including adhesion experiment, freezing front experiment, contact angle approach etc have been used to measure blood cells and protein surface tension and all the approaches used agree with the equation of state approach, thus establishing the impact of surface properties in biological systems.

\subsection{The Concept of Contact Angle}

Precise characterization of solid material surfaces plays a vital role in research and product development in many industrial and academic areas. Wettability of the surface is important in processes like painting and printing, and has been utilized in the study of cell-biomaterial interactions. Contact angle of less than $90^{\circ}\left(\theta<90^{\circ}\right)$ indicates that the wetting of the surface is favorable and the fluid spread over a large area of the surface while an angle greater than $90^{\circ}\left(\theta>90^{\circ}\right)$ generally means that the wetting of the surface under consideration is not favorable and as such the fluid will minimize its contact with the surface to form a compact liquid droplet. More specifically, contact angle of zero $(\theta=0)$ characterizes complete wetting as the droplet turns into a flat puddle [11].

Young equation defines contact angle as:

$$
\gamma_{l v} \cos \theta=\gamma_{s v}-\gamma_{s l}
$$

where $\gamma_{l v}$ represents the liquid-vapor interfacial tension, $\gamma_{s v}$ represents the solid-vapor interfacial tension, $\gamma_{s l}$ represent the solid-liquid interfacial tension and $\theta$ is the contact angle.

It should be emphasized that to obtain finite, measurable contact angle, $\gamma_{l}$ must be greater than $\gamma_{s}$. When $\gamma_{l}<\gamma_{s}$, the liquid forms no contact angle on the solid but spreads and wets it completely. The extent of partial wetting of the solid by the liquid is quantified by the value of $\theta$. The lower value of $\theta$ signifies a better wetting ability and conversely, higher value of $\theta$ indicates a poorly wet surface.

At this point, the spreading coefficient $S$ becomes necessary, which is a measure of the difference in surface energy between the bare dry solid and the moist solid covered by the macroscopic film of liquid.

$$
S=\gamma_{s}-\left(\gamma_{s l}+\gamma_{l}\right)
$$

If $S \geq 0$, spreading occurs (complete wetting), then the work of adhesion is higher than the work of cohesion. When $S$ is negative, the surface prefers to remain dry which is the case of partial wetting. The liquid will only spread to cover part of the solid and in equilibrium will assume a finite contact angle. It is worth stating here that the water contact angle can be taken as a measure of the relative hydrophilicity or hydrophobicity of a given solid. That is the higher the contact angle is, the more hydrophobic the solid surface becomes. In principle, solids having lower surface free energies, $\gamma_{s v}$ exhibit higher values of contact angles [12]. Contact angle hysteresis is the difference in the angle formed as a result of either expanding (advancing) or contracting (receding) of the liquid. The advancing angle approaches a maximum value while receding approaches a minimum value [13].

$$
H=\theta_{a}-\theta_{r}
$$

where $\theta_{a}$ is the advancing angle while $\theta_{r}$ is the receding angle and $H$ is the contact angle hysteresis.

Neumann et al. measured the contact angle of a large number of liquids on solid surfaces, from which a curve of $\gamma_{l v}$ plotted against $\gamma_{l v} \cos \theta$ was obtained and it agrees with the equation of state. The equation of state can be used to determine the value of $\gamma_{s v}$ from a single contact angle and the surface tension of the liquid [14].

$$
\gamma_{l v} \cos \theta=f\left(\gamma_{l v}, \gamma_{s v}\right)
$$


Combining Equations (1.10) and (1.11) yields;

$$
\gamma_{s l}=\gamma_{s v}-f\left(\gamma_{l v}, \gamma_{s v}\right)=f\left(\gamma_{l v}, \gamma_{s v}\right)
$$

The experimental procedure for measuring contact angle and its interpretation in terms of young's equation was analyzed, stressing the need of how efficiently contact angle can be measured with strict adherence [15].

\subsection{Glycerol as Probe Liquid}

Glycerol is completely soluble in water and alcohol. It is slightly soluble in ether, ethyl acetate, and dioxane and insoluble in hydrocarbons. Glycerol has useful solvent properties similar to those of water and simple aliphatic alcohols because of its three-hydroxyl groups. Glycerol is a useful solvent for many solids, both organic and inorganic which is particularly important for the preparation of pharmaceuticals. The solubility of gases in glycerol, like other liquids is temperature and pressure dependent.

The glycerin $\left(\mathrm{C}_{2} \mathrm{H}_{8} \mathrm{O}_{3}\right)$ used as probe liquid for the experiment is an analytical reagent(AR) glycerin having the following composition; minimum assay $99.7 \%$, water insoluble matter $0.003 \%$, Sulphate ash $0.05 \%$, chloride $0.001 \%$, Sulphate $\left(\mathrm{SO}_{4}\right) 0.0025 \%$ and ammonium $0.02 \%$. It is soluble in water and alcohol

\section{MATERIALS AND METHODS}

Standards and universal precautions followed in course of this research were in accordance with the Bloodborne pathogen standards enacted by the Centre for Disease Control(CDC) and also the NCCLS standards were equally observed in the collection, transportation, preparation, storage and safety of the blood specimen used for the experiment. Personal protective equipment (PPE) was equally used in the course of the experiment.

\subsection{Materials and Equipment}

The materials used for this study are disposable syringes and needles, microlitre pipette, HCV test kits, HIV test kits, glycerin solution, test tubes, test tube racks, prepared slides, $5.0 \mu$ microlitre syringe, blood samples, gloves, $150 \mathrm{~mm}$ conical flask, ice pack container, cotton wool, spreader, slide racks.

The following equipment were used for this study; refrigerator, digital electronic balance, partec cyflow counter machine, blood roll mixer, centrifuge machine, incubator, autoclave machine and Nikkon digital camera.

\subsection{Methods}

\subsubsection{Cluster of Differential Cell Count (CD4) of Blood Samples}

Before the beginning of the experiment, the machine was cleaned by inserting into it $1600 \mu \mathrm{l}$ each of cleaning solution, decontamination solution and shealth fluid. $850 \mu \mathrm{l}$ of count check beads green was used on the machine to check for quality control. Quality of 25,100 per ml was obtained which falls between standard acceptable ranges of 23,270 $\mp 10 \%$ per ml. $20 \mu \mathrm{l}$ of CD mAb PE monoclonal antibody was introduced into a sample tube and $20 \mu \mathrm{l}$ of EDTA whole blood was added to the tube and both were gently mixed together. The mixture was incubated for 15 minutes in a dark field at room temperature. Added to the mixture is $800 \mu \mathrm{l}$ of no lysed buffer solution, mixed gently and ran the program. The CD4 cell count on the whole blood samples was obtained using a Partec Cyflow Counter Machine. This helped to determine the level and progression of the HCV depletion of the immune system of the patients. The machine displays automatically the number of CD4 + T cells.

\subsubsection{Blood Sample Separation and Smearing}

The blood samples used for this study include ten samples of hepatitis C infected blood and ten samples of uninfected blood. The samples were collected from Chukwuemeka Odumegwu Ojukwu University 
Teaching Hospital, Amaku in Nigeria.

The samples were stored in an ethyl-diamine-tetra-acetic (EDTA) container to prevent the coagulation of the blood and kept below room temperature in the refrigerator to keep alive the living components in the blood sample before the experiment. The samples were screened for HCV and HIV using test kits and the infection status confirmed to be HCV mono-infected for ten samples and the other ten uninfected. The experiment was carried out at the laboratory Unit of the Chukwuemeka Odumegwu Ojukwu Teaching Hospital, Amaku.

Laboratory activities carried out in the separation of the blood samples, the smearing of the whole blood and its components on the slides are as follows;

$100 \mu \mathrm{l}$ each of infected and uninfected blood serum, white blood cell and red blood cells were smeared on their respective slides using the method of standard smearing and after which the blood samples were placed in the blood roll mixer and all the separated components unified so as to get the whole blood also smeared. The glycerin used as probe liquid for the study was dropped on the surface of the prepared slides using a microliter syringe. Contact was not made between the syringe and the test surface and the droplet volume was small enough to avoid impact effect on the surface and gravity effect negligible. The process of spreading was captured with a high definition Nikkon digital camera and the contact angle was measured. MATLAB computational software was used as a tool for modeling the interactions of HCV-RNA a using the data obtained from the experimental contact angle measurement.

\section{RESULTS AND DISCUSSION}

\subsection{CD4 Count on Immune System of Blood Samples}

Table 1 depicts the CD4 results obtained from the Partec Cyflow Counter Machine for both the infected and uninfected samples. In general, infected samples have low CD4 counts while the uninfected usually have high CD4 cell counts. CD4 cell counts indicate the severity of the hepatitis c virus infection. The highest CD4 count was seen on the uninfected samples while the lowest count was noticed on the infected samples. On the average, infected samples have lower CD4 count which signifies the impact of the hepatitis $\mathrm{C}$ virus in the depletion of the immune system of the infected patients.

Table 1. Measured CD4 counts of infected and uninfected blood samples.

\begin{tabular}{ccc}
\hline Blood Samples (B) & Infected (counts $\left./ \mathrm{mm}^{3}\right)$ & Uninfected $\left(\right.$ counts $\left./ \mathrm{mm}^{3}\right)$ \\
\hline B1 & 428 & 660 \\
B2 & 600 & 872 \\
B3 & 625 & 1780 \\
B4 & 312 & 1450 \\
B5 & 464 & 1500 \\
B6 & 247 & 930 \\
B7 & 852 & 1360 \\
B8 & 115 & 1520 \\
B9 & 704 & 1580 \\
B10 & 798 & 1020 \\
Average & 514.5 & 1267.2 \\
SD & 243.1059 & 368.2731 \\
\hline
\end{tabular}




\subsection{Measured Contact Angles}

The results of contact angles measured can be seen in Table 2 and Table 3. The infected blood was separated according to their respective blood components.

Table 2. Contact angle of infected blood cells.

\begin{tabular}{ccccc}
\hline Blood Samples & Whole Blood $\left(\theta^{\circ}\right)$ & White Blood Cells $\left(\theta^{\circ}\right)$ Red Blood Cells $\left(\theta^{\circ}\right)$ & Serum $\left(\theta^{\circ}\right)$ \\
\hline 1 & 60 & 65 & 59 & 60 \\
2 & 55 & 61 & 64 & 62 \\
3 & 58 & 63 & 58 & 63 \\
4 & 60 & 64 & 57 & 61 \\
5 & 60 & 67 & 56 & 59 \\
6 & 56 & 66 & 62 & 64 \\
7 & 55 & 58 & 63 & 58 \\
8 & 58 & 68 & 61 & 65 \\
9 & 54 & 62 & 60 & 66 \\
10 & 55 & 60 & 64 & 57 \\
Average & 57.1 & 63.4 & 60.4 & 61.5 \\
SD & 2.3781 & 3.2045 & 2.8752 & 3.0277 \\
\hline
\end{tabular}

Table 3. Contact angle of uninfected blood cells.

\begin{tabular}{ccccc}
\hline Blood Samples & Whole Blood $\left(\theta^{\circ}\right)$ & White Blood Cells $\left(\theta^{\circ}\right)$ Red Blood Cells $\left(\theta^{\circ}\right)$ & Serum $\left(\theta^{\circ}\right)$ \\
\hline 1 & 50 & 47 & 48 & 58 \\
2 & 51 & 46 & 57 & 55 \\
3 & 40 & 48 & 45 & 45 \\
4 & 50 & 52 & 50 & 56 \\
5 & 45 & 50 & 52 & 53 \\
6 & 56 & 51 & 51 & 57 \\
7 & 55 & 45 & 49 & 54 \\
8 & 50 & 49 & 54 & 52 \\
9 & 43 & 44 & 47 & 50 \\
10 & 55 & 51 & 53 & 51 \\
Average & 49.5 & 48.5 & 50.6 & 53.1 \\
SD & 5.3593 & 2.7508 & 3.5653 & 3.8427 \\
\hline
\end{tabular}


From the foregoing, it can be deduced that the hepatitis $\mathrm{c}$ virus has the ability of increasing the contact angle of infected surfaces. Hence, infected surfaces are poorly wetted, leading to an increase in contact angle of such surfaces. Among the infected blood components, the white blood cell has the highest contact angle as evident in Figure 1, with a large gap existing between the other components. This leads to a logical conclusion that the white blood cells are the principal target of the virus with sole action of depleting the lymphocytes.

The average contact angle of the infected white blood cells given as $63.4 \pm 3.21$ corresponds to the surface tension of glycerin which is the probe liquid used for this study. This is in accordance with literature report on the contact angle of HIV infected surfaces where the average contact angle of the three probe liquids used yielded same result. It is also in agreement with research result carried out using the equation of state on the surface tension of biological system of infected human lymphocytes [16].

\subsection{Hamaker Coefficient $\left(A_{132}\right)$ of Blood Cells}

The concept of Hamaker coefficient is a function of the net van der Waal force of attraction or repulsion between particles suspended in a liquid. Theoretically a relationship exists between Hamaker coefficient $\left(A_{132}\right)$ and interfacial energies obtained from contact angle data as reported in Equation (1.1). The positive sign on the infected samples depicts attractive forces between the virus and the blood cells which connotes the HCV infection on the blood cells. The uninfected samples also have positive values though of little magnitude signifying the presence of other infections not due to HCV, hence the reason of low CD4 count in some uninfected samples.

Infected surfaces on the average have higher values of Hamaker coefficient than uninfected surfaces as reflected in Table 4. Increase in contact angle causes an increase in Hamaker coefficient with a corresponding decrease in the CD4 counts on the infected surfaces. This increase is attributed to the presence of the HCV virus in the infected samples and the highest value was observed in the white blood cell component.

In contrast, the uninfected surfaces have lower values of Hamaker coefficient with a corresponding decrease in contact angle leading a higher CD4 counts on the uninfected surfaces. Other infections present in the HCV uninfected samples cause the value of Hamaker coefficient to be positive but certainly not hepatitis $C$ virus and the level of infection is insignificant hence a very low Hamaker coefficient value for uninfected surfaces.

\subsection{Response Surface Analysis of Hamaker Coefficient of Infected Blood Cells}

The results obtained from matlab computations were analyzed by applying the coefficient of determination $\left(R^{2}\right)$, lack of fit, response plots and analysis of variance (ANOVA) so as to determine the statistical significance level and generate the model equation which will express the relationship between the predicted response and independent variables in coded values as seen in Table 5 and Table 6.

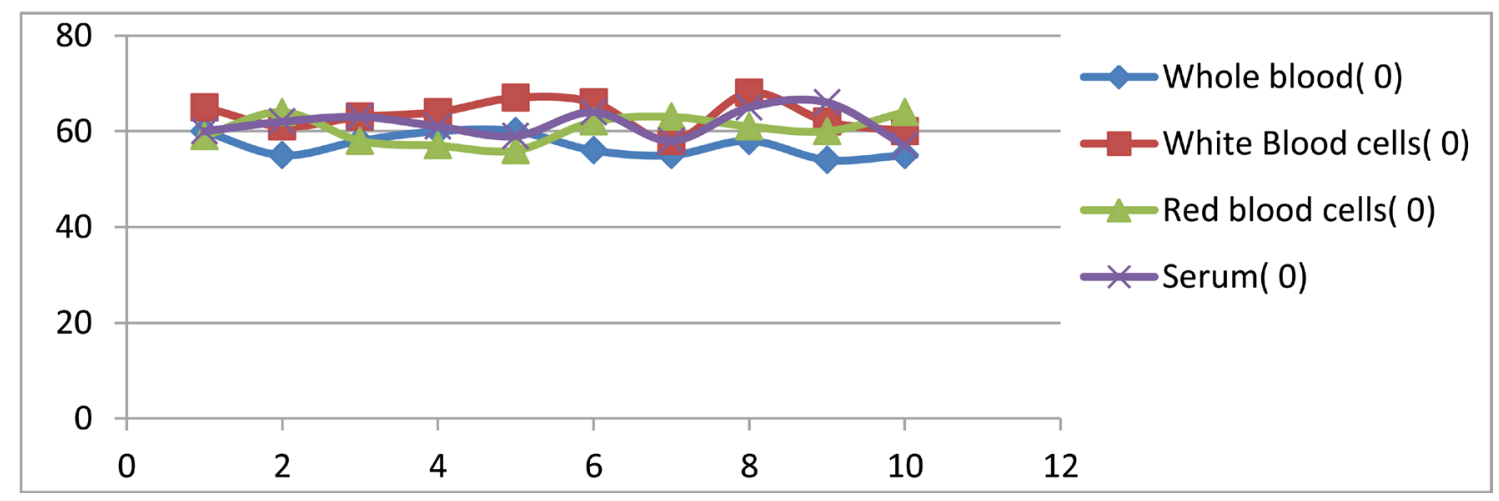

Figure 1. Plot of contact angle versus blood samples. 
Table 4. Hamaker Coefficient Values of Infected and Uninfected Blood Cells

\begin{tabular}{ccccccccc}
\hline & \multicolumn{3}{c}{ White Blood Infected } & \multicolumn{3}{c}{ White Blood Uninfected } \\
\cline { 2 - 8 } SN & $\theta\left({ }^{\circ} \mathrm{C}\right)$ & $A_{132}\left(\mathrm{~mJ} / \mathrm{m}^{2}\right)$ & $\begin{array}{c}\gamma_{s V} \\
\left(\mathrm{~mJ} / \mathrm{m}^{2}\right)\end{array}$ & $\begin{array}{c}F^{a d h} \\
\left(\mathrm{~mJ} / \mathrm{m}^{2}\right)\end{array}$ & $\theta\left({ }^{\circ} \mathrm{C}\right)$ & $A_{132}\left(\mathrm{~mJ} / \mathrm{m}^{2}\right)$ & $\begin{array}{c}\gamma_{s V} \\
\left(\mathrm{~mJ} / \mathrm{m}^{2}\right)\end{array}$ & $\begin{array}{c}F^{a d h} \\
\left(\mathrm{~mJ} / \mathrm{m}^{2}\right)\end{array}$ \\
\hline 1 & 65 & $2.35 \mathrm{E}-17$ & 32.38 & -24.34 & 47 & $1.17 \mathrm{E}-17$ & 45.27 & -12.13 \\
2 & 61 & $2.08 \mathrm{E}-17$ & 35.27 & -21.55 & 46 & $1.11 \mathrm{E}-17$ & 45.95 & -11.50 \\
3 & 63 & $2.21 \mathrm{E}-17$ & 33.83 & -22.95 & 48 & $1.23 \mathrm{E}-17$ & 44.58 & -12.77 \\
4 & 64 & $2.28 \mathrm{E}-17$ & 33.10 & -23.64 & 52 & $1.49 \mathrm{E}-17$ & 41.77 & -15.39 \\
5 & 67 & $2.48 \mathrm{E}-17$ & 30.95 & -25.72 & 50 & $1.36 \mathrm{E}-17$ & 43.18 & -14.06 \\
6 & 66 & $2.42 \mathrm{E}-17$ & 31.66 & -25.03 & 51 & $1.42 \mathrm{E}-17$ & 42.48 & -14.72 \\
7 & 58 & $1.88 \mathrm{E}-17$ & 37.45 & -19.47 & 45 & $1.05 \mathrm{E}-17$ & 46.63 & -10.89 \\
8 & 68 & $2.55 \mathrm{E}-17$ & 30.23 & -26.41 & 49 & $1.29 \mathrm{E}-17$ & 43.88 & -13.41 \\
9 & 62 & $2.15 \mathrm{E}-17$ & 34.55 & -22.25 & 44 & $0.99 \mathrm{E}-17$ & 47.30 & -10.28 \\
10 & 60 & $2.01 \mathrm{E}-17$ & 36.00 & -20.86 & 51 & $1.42 \mathrm{E}-17$ & 42.48 & -14.72 \\
$A V E$ & 63.4 & $2.24 \mathrm{E}-17$ & 33.54 & -23.222 & 48.5 & $1.25 \mathrm{E}-17$ & 44.35 & -12.99 \\
$S D$ & 3.204164 & $2.15 \mathrm{E}-18$ & 2.313597 & 2.225303 & 2.750757 & $1.71 \mathrm{E}-18$ & 1.903218 & 1.758447 \\
\hline & & & & & & &
\end{tabular}

Table 5. ANOVA for Hamaker surface response quadratic model.

\begin{tabular}{ccccccc}
\hline Source & Sum of Squares & D $f$ & Mean Square & F-Value & P-Value Prob $>$ F & \\
\hline Model & 0.45 & 5 & 0.091 & 22.29 & 0.0004 & Significant \\
A-Contact Angle & $3.397 \mathrm{E}-003$ & 1 & $3.397 \mathrm{E}-003$ & 0.83 & 0.3919 & \\
B-Interfacial Energy & 0.11 & 1 & 0.11 & 27.68 & 0.0012 & \\
$\mathrm{AB}$ & 0.053 & 1 & 0.053 & 12.96 & 0.0087 & \\
$\mathrm{~A}^{2}$ & 0.29 & 1 & 0.29 & 69.91 & $<0.0001$ & \\
$\mathrm{~B}^{2}$ & $7.348 \mathrm{E}-003$ & 1 & $7.348 \mathrm{E}-003$ & 1.80 & 0.2215 & \\
Residual & 0.029 & 7 & $4.080 \mathrm{E}-003$ & & & \\
Lack of Fit & 0.016 & 3 & $5.188 \mathrm{E}-003$ & 1.60 & 0.3232 & \\
Pure Error & 0.013 & 4 & $3.250 \mathrm{E}-003$ & & & \\
Cor Total & 0.48 & 12 & & &
\end{tabular}


Table 6. Quadratic model summary.

\begin{tabular}{cc}
\hline Std. Dev. & 0.064 \\
Mean & 2.19 \\
C.V. \% & 2.91 \\
PRESS & 0.13 \\
R-Squared & 0.9409 \\
Adj R-Squared & 0.8987 \\
Pred R-Squared & 0.7290 \\
Adeq Precision & 12.703 \\
\hline
\end{tabular}

The "Pred R-Squared" of 0.7290 is in reasonable agreement with the "Adj R-Squared" of 0.8987; i.e. the difference is less than 0.2. "Adeq Precision" measures the signal to noise ratio. A ratio greater than 4 is desirable. Table 6 predicts a ratio of 12.703 which indicates an adequate signal. This means that the model is a good one for predicting Hamaker coefficient in relation with contact angle and interfacial energy due to HCV infection.

$$
\begin{aligned}
A_{132}= & 2.05-0.021 A+0.12 B+0.12 A B+0.20 A^{2} \\
& +0.033 B^{2}+0.20 A^{2}+0.033 B^{2}
\end{aligned}
$$

The ANOVA indicates the equation and actual relationship between the response and significant variables represented by the Equation (1.13) is accurate. The $\mathrm{R}^{2}$ value of 0.9409 indicates a good measure that outcomes are likely to be predicted well by the developed models. The contour and the surface plot on Figure 2 and Figure 3 also reveal graphically the interaction between the independent variable and the response.

\subsection{Determination of the Negative Hamaker Coefficient}

The concept of negative Hamaker coefficient is a tool employed by this study to check the feasibility of separating the lymphocytes and the hepatitis $C$ virus. It is a principle rooted on the net van der Waal forces of attraction and repulsion. The Hamaker constant of each blood sample is used to predict the attraction or possibly rejection of particulate matters interacting in the system. Table 7 is the computed combined Hamaker constants $A_{11}, A_{22}$ and $A_{33}$ of the total of ten samples of the blood used for this study to yield the average combined negative Hamaker coefficient $\left(A_{132}\right)$ of infected and uninfected blood.

As stated in Equations (1.5) to (1.7), the condition for rendering combined Hamaker coefficient negative is that Hamaker constant $A_{11}$ is greater $A_{33}$ which in turn is also greater than $A_{22}$. The infected lymphocytes are assumed to be an approximation of the virus $A_{22}$. Equations (1.5) and (1.6) can be used to obtain the interaction energy for the lymphocytes and the virus.

The $A_{132}$ of the infected sample was seen to be $-0.150 \times 10^{-18} \mathrm{~mJ} / \mathrm{m}^{2}\left(-0.150 \times 10^{-25} \mathrm{~J}\right)$. This is in agreement with the value reported in literature that HIV infected cell using the Hamaker approach has a combined negative Hamaker of $-0.281 \times 10^{-25} \mathrm{~J}$ [17]. Both results have unveiled the possibility of applying the concept of negative Hamaker as a method of separation of interacting particles.

\section{CONCLUSION}

The measured contact angle data revealed that HCV infected surfaces have higher average contact angles for all blood components than the uninfected sample. In the case of white blood cell, the contact 
Design-Expert® Software

Factor Coding: Actual

Hamaker Coefficient $(\mathrm{E}-17)\left(\mathrm{mJ} / \mathrm{m}^{2}\right)$

- Design Points

П2.48

1.88

X1 = A: Contact Angle X2 = B: Interfacial Energy

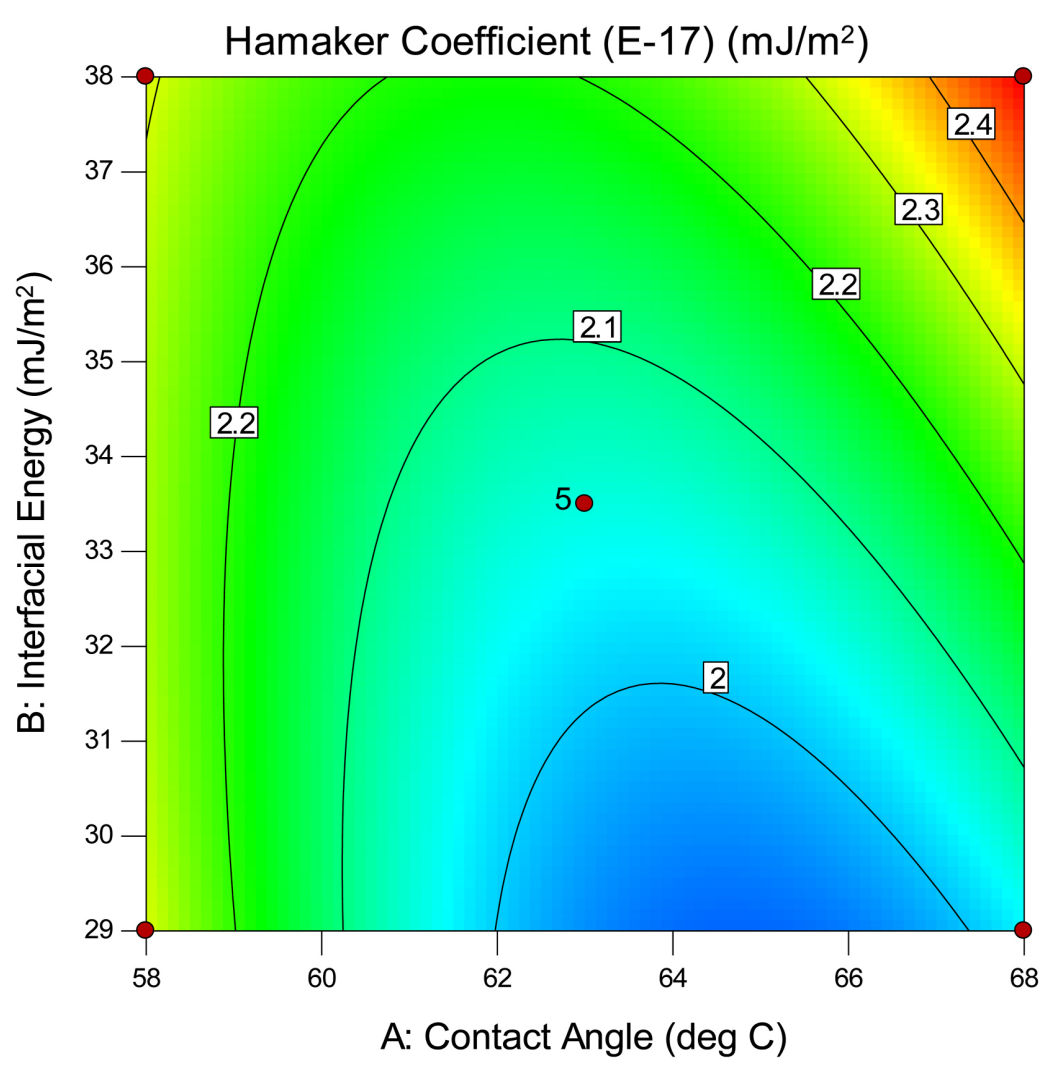

Figure 2. Contour plot of Hamaker coefficient for infected white blood cells.

Design-Expert $\circledast$ Software

Factor Coding: Actual

Hamaker Coefficient $(E-17)\left(\mathrm{mJ} / \mathrm{m}^{2}\right)$

- Design points above predicted value

O Design points below predicted value

2.48

1.88

X1 = A: Contact Angle $\mathrm{X} 2$ = B: Interfacial Energy

\section{$\widetilde{\varepsilon}$}

हิ

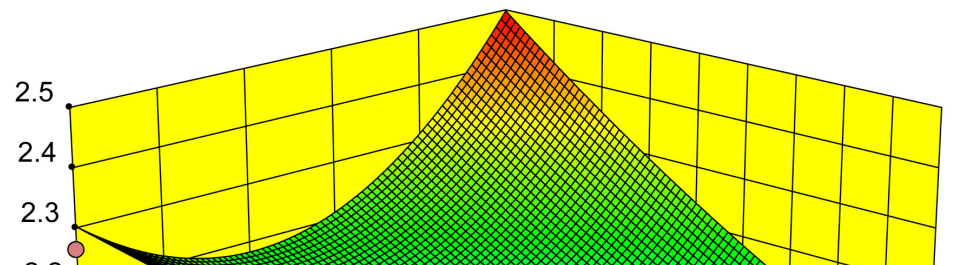

다

몽
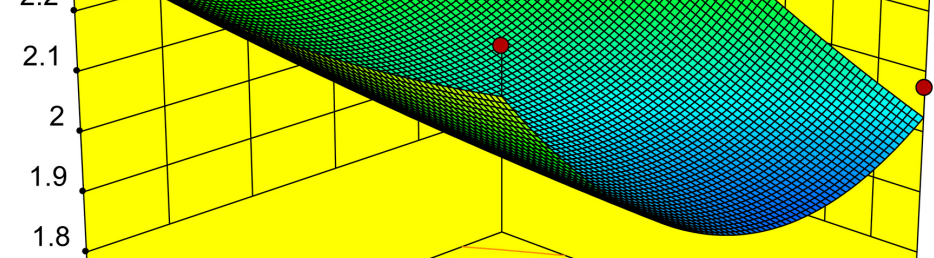

$\frac{\frac{1}{ \pm}}{\frac{1}{\sigma}}$

38

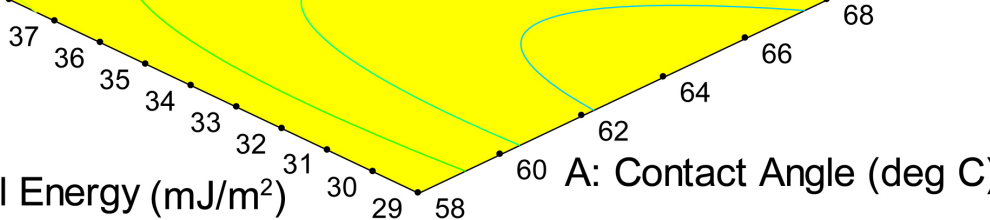

B: Interfacial Energy $\left(\mathrm{mJ} / \mathrm{m}^{2}\right) \quad{ }_{29}{ }_{20}$

Figure 3. 3D surface plot of Hamaker coefficient for infected white blood cells. 
Table 7. Computations for Combined Negative Hamaker Coefficient $\left(\mathrm{mJ} / \mathrm{m}^{2}\right)$

\begin{tabular}{ccccccc}
\hline & $A_{11}\left(\mathrm{~mJ} / \mathrm{m}^{2}\right)$ & $A_{22}\left(\mathrm{~mJ} / \mathrm{m}^{2}\right)$ & $A_{33}\left(\mathrm{~mJ} / \mathrm{m}^{2}\right)$ & $A_{131}\left(\mathrm{~mJ} / \mathrm{m}^{2}\right)$ & $A_{232}\left(\mathrm{~mJ} / \mathrm{m}^{2}\right)$ & $A_{132}\left(\mathrm{~mJ} / \mathrm{m}^{2}\right)$ \\
\hline Infected & & $0.224 \times 10^{-16}$ & $0.211 \times 10^{-16}$ & - & $1.103 \times 10^{-18}$ & $-0.150 \times 10^{-18}$ \\
Uninfected & $0.125 \times 10^{-16}$ & - & $0.160 \times 10^{-16}$ & $0.21 \times 10^{-18}$ & - & - \\
\hline
\end{tabular}

angle of the infected cell is $63.4^{\circ} \pm 3.20^{\circ}$ and uninfected cell is $48.5^{\circ} \pm 2.75^{\circ}$. The presence of the virus in the infected sample causes the surfaces to be poorly wetted and as such leads to an increase in the contact angle. The infected samples subjected to various treatments were observed to exhibit a reduction in measured contact angle. The negative value of the combined Hamaker coefficient $\left(A_{132}\right)$ for HCV infected sample given as $-0.150 \times 10^{-25} \mathrm{~J}$ signifies van der Waal repulsion in the interacting particles indicating that the virus can be isolated from the lymphocyte when the serum acting as the intervening medium is altered. All the drugs used have a reduction effect on the surface energy of the serum $\left(A_{33}\right)$ and an increasing effect on the surface energy of the infected lymphocyte $\left(A_{22}\right)$.

\section{DECLARATION}

Ethical clearance was dully obtained from the relevant authorizing office at Chukwuemeka Odumegwu Ojukwu Teaching Hospital Amaku before this research was conducted.

\section{CONFLICTS OF INTEREST}

The authors declare no conflicts of interest regarding the publication of this paper.

\section{REFERENCES}

1. Lanvanchy, D. (2009) The Global of Hepatitis C. WHO, Geneve, Switzerland. Liver Int. Medical Research.

2. (2013) Albert Lasker Awards for Clinical Medical Research; Year 2000 Winners. World Health Organization: Hepatitis C Facts Sheet. No: 164. Retreieved $24^{\text {th }}$ Sept, 2016. http://www.laskerfoundation.org/awards

3. Ray, S.C. and Thomas, D.L. (2010) Principles and Practices of Infectious Disease. Churchill Livingstone, Elsevier Publishers, Philadephia, 2157-2185.

4. Abdelwahab, K.S. and Ahmed, Z.N. (2018) Status of Hepatitis C Virus Vaccination. World Journal of Gastroenterology, 22, 862-873. https://doi.org/10.3748/wig.v22.i2.862

5. Shiffman, M.I., Salvatore, J. and Hubbard, S. (2007) Treatment of Chronic Hepatitis C Virus with Peg-Interferon, Ribavirin and Epotein Alpha. Hepatology, 46, 371-379. https://doi.org/10.1002/hep.21712

6. Achebe, C.H., Omenyi, S.N., Manafa, O.P. and Okoli, D. (2012) HIV-Blood Interactions; Surface Thermodynamics Approach. Proceedings of the International Conference of Engineers and Computer Scientist, Hong Kong, 136-141.

7. Chukwuneke, J.L. (2015) Surface Energetic Study of MTB. Ph.D. Thesis, UNIZIK, Awka.

8. Hamaker, H.C. (1936) The London/Van der Wall Attraction between Spherical Particles. Physics, 4, 1058.

9. Omenyi, S.N., Newmann, A.W., Van Oss, C.J., Absolom, D.R. and Viser, J. (1980) Separation and Purification Methods. Advance Colloid Interface Sci., 18, 133.

10. Ani, O.I. (2016) Surface Energetics Study of the Interaction between HIV-Blood Blood Cells Treated with Antiretroviral Drugs. Ph.D. Thesis, UNIZIK, Nigeria.

11. Yuan, Y. and Lee, R. (2013) Contact Angle and Wetting Properties. University of Houston, Texas.

12. Rullison, C. (2008) Comparison of Different Methods to Measure Contact Angles of Soil Colloids. Journal of 
Colloids and Interface Science, 328, 299-307. https://doi.org/10.1016/j.jcis.2008.09.039

13. Krumpfer, J.W., McCarthy, T.J. and Gao, L. (2010) Wetting Properties of Fluids. Physics of Fluids, Faraday Discussions, 146, 103. https://doi.org/10.1039/b925045j

14. Neumann, A.W., Good, R.J., Hope, C.J. and Segpal, M. (1974) Colloids and Interfaces; Equation of State Approach to Determine the Surface Tension of Low Energy Fluids from Contact Angle. Journal of Colloid and Interface Science, 49, 291-304. https://doi.org/10.1016/0021-9797(74)90365-8

15. Kwok, D.Y. and Neumann, A.W. (1999) Contact Angle Measurements and Contact Angle Interpretation. Advances in Colloid and Interface Science, 81, 167-249. https://doi.org/10.1016/S0001-8686(98)00087-6

16. Ozoihu E.M. (2014) Human Immunodeficiency Virus; Contact Angle Approach. Ph.D. Thesis, Nnamdi Azikiwe University, Awka.

17. Achebe, C.H. and Omenyi, S.N. (2013) Mathematical Determination of the Critical Absolute Hamaker Constant of the Serum (as Intervening Medium) Which Favors Repulsion in HIV-Blood Interactions Mechanism. Proceedings of World Congress on Engineering, London, 3-5 July 2013, 1380-1384.

\section{ABBREVATIONS}

Cluster of Differentiation 4 (CD4), Human immunodeficiency virus (HIV), Hepatitis c virus (HCV), Ribonucleic Acid (RNA), Combined Negative Hamaker coefficient $\left(\mathrm{A}_{132}\right)$ 